\title{
Changes in understory species occurrence of a secondary broadleaved forest after mass mortality of oak trees under deer foraging pressure
}

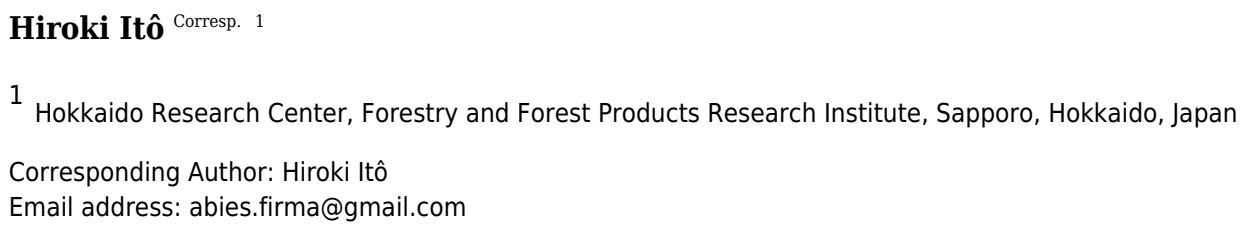

The epidemic of mass mortality of oak trees by Japanese oak wilt has affected secondary deciduous broadleaved forests that have been used as coppices in Japan. The dieback of oak trees formed gaps in the crown that would be expected to enhance the regeneration of shade-intolerant pioneer species. However, foraging by sika deer Cervus nippon has also affected forest vegetation, and the compound effects of both on forest regeneration should be considered when they simultaneously occur. A field study was conducted in Kyôto City, Japan, to investigate how these compound effects affected the vegetation of the understory layer of these forests. The presence/absence of seedlings and saplings was observed for 200 quadrats sized $5 \mathrm{~m} \times 5 \mathrm{~m}$ for each species in 1992, before the mass mortality and deer encroachment, and in 2014 after these effects. A hierarchical Bayesian model was constructed to explain the occurrence, survival, and colonization of each species with their responses to the gaps that were created, expanded, or affected by the mass mortality of Quercus serrata trees. The species that occurred most frequently in 1992, Eurya japonica, Quercus glauca, and Cleyera japonica, also had the highest survival probabilities. Deer-unpalatable species such as Symplocos prunifolia and Triadica sebifera had higher colonization rates in the gaps, while the deer-palatable species Aucuba japonica had the smallest survival probability. The gaps thus promoted the colonization of deer-unpalatable plant species such as Symplocos prunifolia and Triadica sebifera. In the future, such deer-unpalatable species may dominate gaps that were created, expanded, or affected by the mass mortality of oak trees. 


\section{Changes in understory species occurrence of a secondary broadleaved forest after mass mortality of oak trees under deer foraging pressure}

\section{Hiroki Itô ${ }^{1}$}

${ }^{1}$ Hokkaido Research Center, Forestry and Forest Products Research Institute, Toyohira, Sapporo 305-8687, Japan. Email address:abies.firma@gmail.com

\section{ABSTRACT}

The epidemic of mass mortality of oak trees by Japanese oak wilt has affected secondary deciduous broadleaved forests that have been used as coppices in Japan. The dieback of oak trees formed gaps in the crown that would be expected to enhance the regeneration of shade-intolerant pioneer species. However, foraging by sika deer Cervus nippon has also affected forest vegetation, and the compound effects of both on forest regeneration should be considered when they simultaneously occur. A field study was conducted in Kyôto City, Japan, to investigate how these compound effects affected the vegetation of the understory layer of these forests. The presence/absence of seedlings and saplings was observed for 200 quadrats sized $5 \mathrm{~m} \times 5 \mathrm{~m}$ for each species in 1992, before the mass mortality and deer encroachment, and in 2014 after these effects. A hierarchical Bayesian model was constructed to explain the occurrence, survival, and colonization of each species with their responses to the gaps that were created, expanded, or affected by the mass mortality of Quercus serrata trees. The species that occurred most frequently in 1992, Eurya japonica, Quercus glauca, and Cleyera japonica, also had the highest survival probabilities. Deer-unpalatable species such as Symplocos prunifolia and Triadica sebifera had higher colonization rates in the gaps, while the deer-palatable species Aucuba japonica had the smallest survival probability. The gaps thus promoted the colonization of deer-unpalatable plant species such as Symplocos prunifolia and Triadica sebifera. In the future, such deer-unpalatable species may dominate gaps that were created, expanded, or affected by the mass mortality of oak trees.

Keywords: deer-unpalatable plant species, gap, Japanese oak wilt, sika deer, understory vegetation

\section{INTRODUCTION}

Many coppices have been abandoned for socio-economic reasons, such as the replacement of woody fuels with fossil fuels in Europe (Rackham, 2008; Müllerová et al., 2015; Svátek and Matula, 2015). This abandonment parallels that of Japan (Suzuki, 2013), and a considerable number of deciduous oak forests grown from such coppices have suffered from the mass mortality of oak trees (Kuroda et al., 2012; Nakajima and Ishida, 2014) caused by Japanese oak wilt (Kuroda et al., 2012). The direct cause of the 
mortality is a pathogenic species of fungus Raffaelea quercivora Kubono et Shin. Ito, which is carried by the ambrosia beetle Platypus quercivorus Murayama (Kubono and Ito, 2002; Kinuura and Kobayashi, 2006). In addition, it has been pointed out that the coppice abandonment is an indirect cause of the epidemic because the ambrosia beetles reproduce more successfully in large oak stems, which are more abundant as abandoned oak stems grow up (Kobayashi and Ueda, 2005). There is another possible reason why the abandonment indirectly affected the epidemic: in the period when coppices were managed, oak stems that died from the wilt were quickly felled and utilized for fuel or charcoal, and as a result, it prevented outbreaks of the disease (Ida and Takahashi, 2010).

The mass mortality altered the structures of damaged oak forests. The two major deciduous oak species in Japan, Quercus crispula Blume and Quercus serrata Murray, are vulnerable to the pathogenic fungus. Nakajima and Ishida (2014) showed that 80 $\pm 19 \%$ (mean \pm standard deviation) stems of Quercus crispula died, while $34 \pm 19 \%$ stems of Quercus serrata died. Naka (1982) studied an old-growth evergreen forest in the Kasugayama Forest Reserve in Nara City, which is located about $40 \mathrm{~km}$ south of the study site, and showed that the major gap generator was typhoons, and that the interval between the typhoon disturbances was 6.57 years with a tree fall rate for overstory trees of 0.84 trees/ha/year, and that the canopy opening rate was $55.6 \mathrm{~m}^{2} / \mathrm{ha} / \mathrm{year}$. Though these rates are not directly applicable to deciduous secondary oak forests, the gaps created by the mortality would not be negligible for oak-dominated forests. If Quercus serrata covers $30 \%$ of the canopy and $30 \%$ of them die, $900 \mathrm{~m}^{2}$ / ha of the canopy will become gaps. How such damaged oak forests regenerate depends on the circumstances; sub-canopy trees might grow to canopy trees in some cases (Itô et al., 2009), and dense floor vegetation such as dwarf bamboo might inhibit regeneration in other cases (Itô et al., 2011; Saito and Shibata, 2012). In the latter case, the damaged forests may lack a canopy layer for a long time.

For the last several decades,herbivory by overabundant deer populations has negatively affected forest vegetation in Europe and North America (Rooney, 2001; Côté et al., 2004; Rackham, 2008). This is paralleled in Japan: sika deer (Cervus nippon Temminck) is one major inhibitor of forest regeneration (Takatsuki, 2009; Suzuki, 2013; Iijima and Nagaike, 2015). However, little is known about how regeneration proceeds after mass mortality under deer foraging pressure (Obora et al., 2013). Gap formation should improve light conditions on the forest floor and promote the regeneration of many tree species (Suzuki, 2013). However, excessive browsing should inhibit regeneration, except for unpalatable and browse-tolerant species (Shimoda et al., 1994). Therefore, a combination of both factors might promote the regeneration of species that are unpalatable and/or browse-tolerant to deer. This in turn may alter the species composition of forests that regenerate from the mass mortality of oak trees over time.

It is important for the management of secondary forests to predict what tree or shrub species will be recruited in forest stands damaged by the mass mortality of oak trees and deer impact. In a previous study, Itô (2015) described the changes in the canopy/sub-canopy and understory layers of a damaged forest by comparing vegetation before and after mass mortality of oak trees and deer foraging. It was found that regenerating species were limited to the originally abundant species, such as Quercus glauca Thunb., Cleyera japonica Thunb., and Eurya japonica Thunb. var. japonica, as well as to species unpalatable to deer, such as Symplocos prunifolia Siebold 
et Zucc. and Triadica sebifera (L.) Small. However, the study only described the changes in species occurrence and failed to estimate the specific probabilities of survival and colonization. In this study, the previous data from the understory layers were reanalyzed using a hierarchical Bayesian model that explicitly incorporates probabilities of ecological processes such as occurrence, survival, and colonization. A hierarchical model incorporating random species effects also makes it possible to estimate those probabilities by species, "borrowing strength from the ensemble" (Kéry and Schaub, 2012). These advantages should be of use in predicting which species will dominate such stands in the future.

\section{MATERIALS AND METHODS}

\section{Study site}

The field data were collected in the Ginkakuzi-san (also spelled Ginkakuji-san) National Forest located in Kyôto City, Japan $\left(35.029^{\circ} \mathrm{N}, 135.801^{\circ} \mathrm{E}\right)$. The yearly average temperature from 1981 to 2010 was $15.9^{\circ} \mathrm{C}$ and the average precipitation was $1491.3 \mathrm{~mm}$ at the Kyôto Local Meteorological Office. Elevation of the forest was 100-290 m above sea level, and the forest was in the warm temperate zone. The national forest was protected for its landscape and erosion control, and most of it was situated in the buffer zone of the UNESCO world heritage site, historic monuments of ancient Kyôto. The fieldwork was conducted with permission under an agreement between the Kyôto-Ôsaka District Forest Office and the Forestry and Forest Products Research Institute.

In the 1930s, most of the forest canopy consisted of a mix of pines (Pinus densiflora Siebold et Zucc.) and broadleaved trees including oak (Quercus serrata). After the 1960s, many pine trees had died due to the pine wilt disease. Recently, most of the national forest has been covered with a secondary broadleaved forest consisting of many species such as evergreen oak Quercus glauca, evergreen subcanopy species Symplocos prunifolia, and deciduous tree species Ilex macropoda Miq., although conifers (Cryptomeria japonica (L.f.) D.Don and Chamaecyparis obtusa (Siebold et Zucc.) Endl.) were planted in a small part of the area (Itô, 2007). In 2005, the mass mortality of oaks was first recognized in the eastern part of Kyôto City, in which the Ginkakuzi-san National Forest is located, and then the damage expanded (Itô, 2015). In addition, damage by sika deer resulting from browsing and bark-stripping has been noticeable over the same period. Deer had been seldom seen in the 1990s (personal observation), but by this time inhabited the forest throughout the year (Itô, 2015).

In 1992 , a 0.5 ha $(100 \times 50 \mathrm{~m})$ plot was established on a south-facing slope in the national forest at an elevation of 140-195 m. The average slope inclination was about $30^{\circ}$ and the surface geology was granite. All the stems in the plot were marked and their diameters at breast height (dbh) were measured in 1993, 1996, 1999, 2002, 2005, and 2014. Mainly due to the mass mortality of oak trees Quercus serrata, the basal area in the plot decreased from $43.3 \mathrm{~m}^{2} /$ ha in 2005 to $39.5 \mathrm{~m}^{2} /$ ha in 2014 , while the number of stems in the plot increased from 1554 to $1645(3108$ stems/ha to 3290 stems/ha in stem density). There were 36 Quercus serrata stems in the plot in 2005, and 21 of them died by 2014. These trees were most likely killed by Japanese oak wilt. This affected the forest structure in the plot via the formation of new canopy gaps or by expanding existing gaps. In some area, the mortality indirectly affected the forest floor 
via treatments of dead stems by the forest office (cutting down the stems, cutting the fallen stems into pieces, and disinfecting them) (Itô, 2015). On the other hand, none of the evergreen oaks Quercus glauca died from the disease, though some were attacked by the ambrosia beetles, being less vulnerable than Quercus serrata (Murata et al., 2005, 2009). In the understory layer, Quercus glauca and some evergreen shrub species such as Eurya japonica and Cleyera japonica were frequently observed. Overall changes in the species composition of the site from 1990s to 2010s were reported in Itô (2015).

\section{Data collection}

The plot was divided into 200 quadrats sized $5 \mathrm{~m} \times 5 \mathrm{~m}$. In 1992, all woody plant seedling or saplings (age $\geq 1$ year and $\mathrm{dbh}<3 \mathrm{~cm}$ ) were tallied by species. The plots were resampled in 2014. In 2014, each quadrat was classified into inside or outside of gaps formed by the death of oak trees or older gaps that were affected in addition by fallen dead oak trees. Quadrats on the boundary were visually classified; if an open area which was created, expanded, or affected by the mass morality occupied most of the quadrat, the quadrat was classified as a gap quadrat. Twenty of 200 quadrats were classified as gaps created or affected by oak death (Fig. 1). The size of the largest gap was approximately $250 \mathrm{~m}^{2}$ consisting of 10 adjacent quadrats.

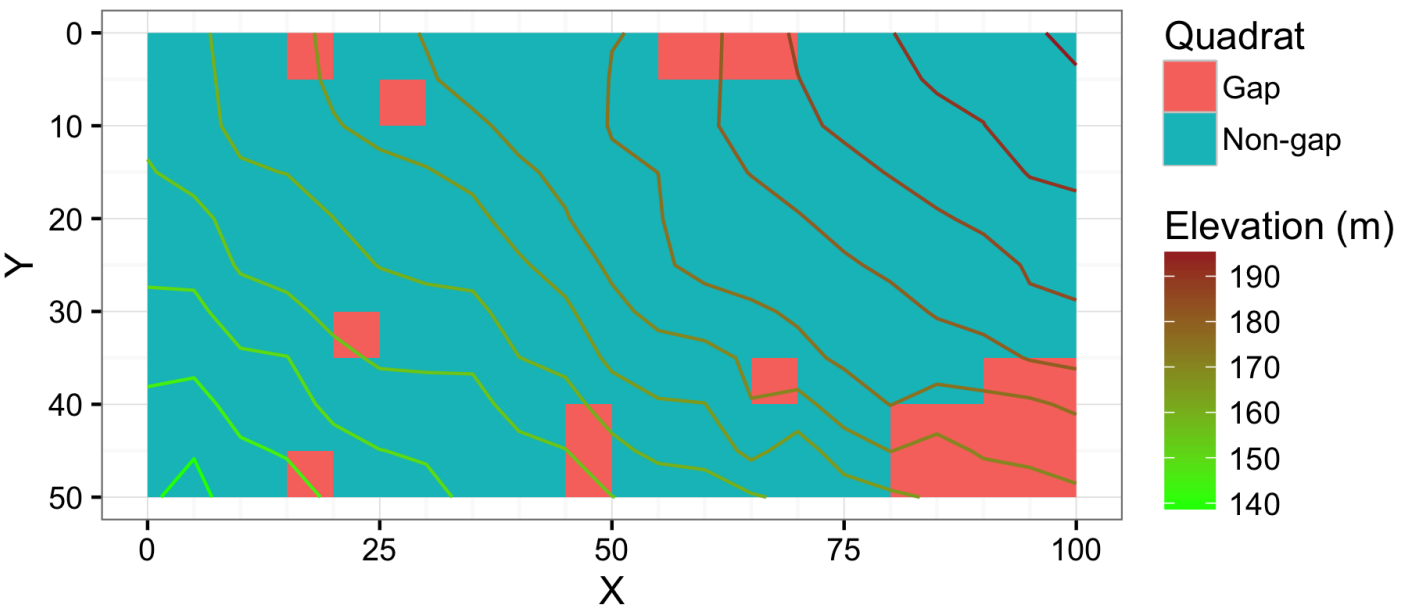

Figure 1. Map showing the study site.

Gap denotes the gap quadrats created, expanded, or affected by the mass mortality of oak trees. Non-gap denotes the rest of the quadrats. Units of the $\mathrm{X}$ and $\mathrm{Y}$ axes are in meters.

In 1992, 55 species were observed and 58 species were observed in 2014 (Itô, 2015), amounting to 75 species in total over both years. The species with highest frequency of occurrence over quadrats in 1992 were Quercus glauca and Eurya japonica, both of which were observed in 184 of 200 quadrats. The mean and median numbers of quadrats in 1992 in which a given species occurred were 19.5 and 4, respectively, excluding species which were not present in 1992. On the other hand, the maximum in 2014 was 
193 for Quercus glauca. The mean and median were 15.6 and 5, respectively, excluding species which did not occur in 2014 in any quadrats.

Data analysis was conducted for 42 of the species that were observed in more than 5 quadrats over both sample years (200 quadrats $\times 2$ observations).

\section{Statistical Modeling}

A hierarchical Bayesian model was constructed to determine how species were affected by the recent environmental changes in the forest.

The presence/absence (presence $=1$, absence $=0$ ) of species $i$ in quadrat $j$ in the year $1992\left(y_{1 i j}\right)$ and $2014\left(y_{2 i j}\right)$ was assumed to follow the Bernoulli distribution given the occurrence probability $\psi_{1 i j}$ and $\psi_{2 i j}$, as follows,

$$
\begin{aligned}
& y_{1 i j} \sim \operatorname{Bernoulli}\left(\psi_{1 i j}\right) \\
& y_{2 i j} \sim \operatorname{Bernoulli}\left(\psi_{2 i j}\right) .
\end{aligned}
$$

To be exact, the "presence/absence" was "detection/nondetection" (Dorazio et al., 2006; Kéry and Schaub, 2012). It has been pointed out that detection probability should be considered to correctly estimate population properties such as the occurrence rate or survival rate, even if the observed objects are plants (Kéry, 2004; Chen et al., 2009, 2013). The present study had only one observation for each survey year. However, the quadrat size was rather small $(5 \mathrm{~m} \times 5 \mathrm{~m})$ and the whole of each quadrat was explored, so I expected that the detection probability should be near to one and therefore "detection/nondetection" was regarded as "presence/absence" in this study. Chen et al. (2009) showed that the detection probability asymptotically approaches one with larger survey efforts.

The parameter of occurrence in $1992, \psi_{1 i j}$, was formulated as follows:

$$
\operatorname{logit}\left(\psi_{1 i j}\right)=\beta_{\mathrm{o}}+\varepsilon_{\mathrm{o} i}+r_{j}
$$

where $\beta_{\mathrm{o}}$ denotes an intercept or overall mean of $\psi_{1}$ on the logit scale, and $\varepsilon_{o i}$ denotes the random species effect on the intercept of species $i$. The parameter $r_{j}$ denotes a spatially autocorrelated random effect of quadrat $j$.

The parameter of occurrence in $2014, \psi_{2 i j}$, was formulated as follows:

$$
\psi_{2 i j}=y_{1 i j} \phi_{i j}+\left(1-y_{1 i j}\right) \gamma_{i j},
$$

where parameter $\phi_{i j}$ denotes the 'survival' probability that species $i$ was present in quadrat $j$ in 1992 and still present in 2014. The parameter $\gamma_{i j}$ denotes the 'colonization' probability that species $i$ was absent in quadrat $j$ in 1992 but present in 2014.

The parameters of survival $\phi_{i j}$ and colonization $\gamma_{i j}$ were formulated as follows:

$$
\begin{aligned}
& \operatorname{logit}\left(\phi_{i j}\right)=\beta_{\mathrm{s}}+\varepsilon_{\mathrm{s} i}+\left(\beta_{\mathrm{sg}}+\varepsilon_{\mathrm{sg} i}\right) g_{j} \\
& \operatorname{logit}\left(\gamma_{i j}\right)=\beta_{\mathrm{c}}+\varepsilon_{\mathrm{c} i}+\left(\beta_{\mathrm{cg}}+\varepsilon_{\mathrm{cg} i}\right) g_{j},
\end{aligned}
$$

where the parameters $\beta_{\mathrm{s}}$ and $\beta_{\mathrm{c}}$ are intercepts or overall means of $\phi$ and $\gamma$ on the logit scale, respectively. The parameters $\varepsilon_{s i}$ and $\varepsilon_{c i}$ are random species effects on the 
intercepts, $\beta_{\mathrm{sg}}$ and $\beta_{\mathrm{cg}}$ are coefficients of the gap predictor $g_{j}(0$ : non-gap quadrats, 1 : gap quadrats affected by oak mortality), and $\varepsilon_{\mathrm{sg} i}$ and $\varepsilon_{\mathrm{cg} i}$ are random species effects on the coefficients.

Priors of the random species effects were defined hierarchically; hyperparameters, $\sigma_{\mathrm{o}}, \sigma_{\mathrm{s}}, \sigma_{\mathrm{sg}}, \sigma_{\mathrm{c}}$, and $\sigma_{\mathrm{cg}}$ scaled the distribution of $\varepsilon_{\mathrm{o} i}, \varepsilon_{\mathrm{s} i}, \varepsilon_{\mathrm{sg} i}, \varepsilon_{\mathrm{c} i}$, and $\varepsilon_{\mathrm{cg} i}$, respectively, as follows:

$$
\varepsilon_{\mathrm{o} i} \sim \operatorname{Normal}\left(0, \sigma_{\mathrm{o}}^{2}\right) \mathrm{T}(-10,10),
$$

where $\operatorname{Normal}\left(0, \sigma^{2}\right) \mathrm{T}(-10,10)$ denotes a normal distribution truncated at -10 and 10; the truncation was incorporated to stabilize the logit scale parameters (Kéry and Schaub, 2012). Priors of the parameters $\beta_{\mathrm{o}}, \beta_{\mathrm{op}}, \beta_{\mathrm{os}}, \beta_{\mathrm{s}}, \beta_{\mathrm{sg}}, \beta_{\mathrm{c}}$, and $\beta_{\mathrm{cg}}$ were defined as $\operatorname{Normal}\left(0,10^{4}\right) \mathrm{T}(-10,10)$. The prior of the spatial effect $r_{j}$ was defined as an intrinsic conditional autoregressive model as follows:

$$
r_{j} \mid r_{-j} \sim \operatorname{Normal}\left(\sum_{k \neq j} \frac{w_{j k} r_{j}}{w_{j+}}, \frac{\sigma_{r}^{2}}{w_{j+}}\right),
$$

where $r_{-j}$ denote the values of $r$ except for the quadrat $j$, a variable $w_{j k}$ was defined to be 1 if quadrat $j$ and quadrat $k$ are adjacent, and 0 if not, and $w_{j+}$ was defined to be $\sum_{k} w_{j k}$. The parameter $\sigma_{r}^{2}$ denotes a variance of the random effect.

Presence/absence data for 42 species, which were observed in more than 5 quadrats in total over two surveys, 1992 and 2014, were used for the parameter estimation. To estimate the posterior distribution for each parameter, the Markov chain Monte Carlo (MCMC) method was adopted; this simulation method generates Markov chains drawing values from the target posterior distributions if the chains converge to stationary distributions (Gelman et al., 2013). Four parallel chains were generated in this study, and each of them had 13,000 iterations while the first 3,000 iterations were dropped as burn-in. The MCMC sample was taken from the three chains with 10 thinning intervals, so that the sample size was 4,000. OpenBUGS 3.2.3 (Lunn et al., 2009) was used for the computation. The BUGS code is available in List S2. To check the convergence, Gelman-Rubin statistics $(\hat{R})$ were calculated (Gelman and Rubin, 1992; Brooks and Gelman, 1998; Gelman et al., 2013). When the Markov chains successfully converge, the value of $\hat{R}$ becomes nearly one. If the value of $\hat{R}$ is no larger than 1.1 , the chains are usually regarded as converged (Kéry and Schaub, 2012).

\section{RESULTS}

For each parameter, the values of $\hat{R}$ were no larger than 1.1, so that the Markov chains seemed to reach convergence. However, some random species effects on coefficients of gaps had rather wide posteriors as mentioned later. Those parameters might lack enough information to obtain satisfactory estimates.

Posterior mean, median, and 95\% credible interval (CI) of the overall occurrence probability in 1992 (probability that a species was present in a quadrat in 1992), $\beta_{\mathrm{o}}$, was estimated to be -3.25 for the posterior mean, -3.25 for the median, and -3.99 to 
-2.54 for the $95 \% \mathrm{CI}$ (Table 1). The value -3.25 on the logit scale is equivalent to 0.037 $(=1 /(1+\exp (3.25)))$ on the probability scale. Therefore, a species was expected to occur in $3.7 \%$ of quadrats on average in 1992. In the same manner, the $95 \% \mathrm{CI}$ was $1.8-7.3 \%$ on the probability scale.

The overall survival probability (probability that a species was present in a quadrat in 1992 and still present in the same quadrat in 2014), $\beta_{\mathrm{s}}$, was estimated to be -2.60 for the posterior mean, -2.57 for the median, and -4.11 to -1.44 for the $95 \%$ CI. The mean value was equivalent to a probability that a species occurring in 1992 surviving in the same quadrat in 2014 was expected to be $6.9 \%$, and the $95 \%$ CI was 1.6-19.2\%.

On the other hand, the overall colonization probability (probability that a species was absent in a quadrat in 1992 but present in the same quadrat in 2014), $\beta_{\mathrm{c}}$, was estimated to be -3.81 for the posterior mean, -3.81 for the median, and -4.45 to -3.18 for the $95 \%$ CI. The value -3.81 was equivalent to 0.022 on the probability scale; so that the probability that a species which was absent in a quadrat in 1992 had colonized into the quadrat in 2014 was expected to be $2.2 \%$, and the $95 \%$ CI was $1.2-4.0 \%$.

Posterior mean of coefficients of the gap effect on survival $\beta_{\mathrm{sg}}$ and colonization $\beta_{\mathrm{cg}}$ were -0.17 and 1.51 , respectively, and $\beta_{\mathrm{cg}}$ did not include zero in the $95 \% \mathrm{CI}$ (0.86-2.08), while $\beta_{\mathrm{sg}}$ included zero in the $90 \% \mathrm{CI}(-1.27-0.81)$. The mean value 1.51 of $\beta_{\mathrm{cg}}$ meant that gaps increased average colonization probability from $2.2 \%$ to $9.1 \%$ $(=1 /(1+\exp (3.81-1.51))$ on average.

Table 1. Parameter estimates (posterior mean, standard deviation (SD), and $2.5 \%, 5 \%$, $50 \%, 95 \%$, and $97.5 \%$ quantiles) other than random effects.

Positive values of the intercepts $\left(\beta_{\mathrm{o}}, \beta_{\mathrm{s}}\right.$, and $\left.\beta_{\mathrm{c}}\right)$ on the logit scale mean that the corresponding probabilities are larger than 0.5 , and vice versa. Positive values of the coefficients of gap ( $\beta_{\mathrm{sg}}$ and $\beta_{\mathrm{cg}}$ ) mean that the gap increases the corresponding probabilities. Parameters $\sigma_{\mathrm{o}}$ and below are standard deviations of the corresponding predictors.

\begin{tabular}{rrrrrrrr}
\hline & Mean & SD & $2.5 \%$ & $5 \%$ & $50 \%$ & $95 \%$ & $97.5 \%$ \\
\hline$\beta_{\mathrm{o}}$ & -3.25 & 0.37 & -3.99 & -3.88 & -3.25 & -2.65 & -2.54 \\
$\beta_{\mathrm{s}}$ & -2.60 & 0.67 & -4.11 & -3.81 & -2.57 & -1.61 & -1.44 \\
$\beta_{\mathrm{sg}}$ & -0.17 & 0.65 & -1.54 & -1.27 & -0.14 & 0.81 & 1.04 \\
$\beta_{\mathrm{c}}$ & -3.81 & 0.32 & -4.45 & -4.33 & -3.81 & -3.28 & -3.18 \\
$\beta_{\mathrm{cg}}$ & 1.51 & 0.31 & 0.86 & 0.98 & 1.53 & 1.99 & 2.08 \\
$\sigma_{\mathrm{o}}$ & 2.27 & 0.30 & 1.76 & 1.82 & 2.24 & 2.81 & 2.95 \\
$\sigma_{\mathrm{s}}$ & 2.89 & 0.57 & 1.97 & 2.07 & 2.84 & 3.91 & 4.13 \\
$\sigma_{\mathrm{sg}}$ & 1.51 & 0.84 & 0.19 & 0.31 & 1.40 & 3.07 & 3.48 \\
$\sigma_{\mathrm{c}}$ & 1.89 & 0.28 & 1.43 & 1.48 & 1.86 & 2.40 & 2.51 \\
$\sigma_{\mathrm{cg}}$ & 1.35 & 0.32 & 0.81 & 0.88 & 1.32 & 1.93 & 2.07 \\
$\sigma_{\mathrm{r}}$ & 0.44 & 0.10 & 0.27 & 0.29 & 0.44 & 0.60 & 0.65 \\
\hline
\end{tabular}

Random species effects on occurrence probability in $1992\left(\varepsilon_{0}\right)$ are shown in Fig. 2. Eurya japonica and Quercus glauca had the largest value, followed by Cleyera japonica, Aucuba japonica Thunb. var. japonica, Ilex crenata Thunb., Photinia glabra (Thunb.) Maxim., and so on. The posterior mean for Eurya japonica and Quercus glauca was 5.71, 
and this meant that the occurrence probability of the species increased from an overall mean of $3.7 \%$ to $92.1 \%(=1 /(1+\exp (3.25-5.71)))$. The $95 \% \mathrm{CI}$ of the random species effect for Eurya japonica, 4.85-6.62, corresponded to $83.2-96.7 \%$ for the occurrence probability for the species. In the same manner, the expected occurrence probabilities were $59.1 \%$ for Cleyera japonica, 53.2\% for Aucuba japonica, 34.8\% for Ilex crenata, and $31.6 \%$ for Photinia glabra. On the other hand, Carpinus tschonoskii Maxim., Celtis sinensis, Zanthoxylum ailanthoides Siebold et Zucc., and Triadica sebifera had the smallest values because these species were not detected in 1992 (Fig. 2). The posterior mean for Carpinus tschonoskii was -3.21 on the logit scale and the expected occurrence was $0.2 \%(=1 /(1+\exp (3.25+3.21)))$ on the probability scale. The $95 \%$ CI of the species, -6.08 to -1.11 , corresponded to an occurrence probability of $0.0-1.3 \%$ on the probability scale.

Random species effects on the intercept of survival from 1992 to $2014\left(\varepsilon_{\mathrm{s}}\right)$ are shown in Fig. 3A. Quercus glauca had the largest value, and Cleyera japonica, Eurya japonica, and Camellia japonica L. followed. The posterior mean of Quercus glauca was 5.93, and the expected survival probability was $96.5 \%(=1 /(1+\exp (2.60-5.93)))$ without the gap effects. The expected survival probabilities were $88.3 \%$ for Cleyera japonica, 76.7\% for Eurya japonica, and 55.7\% for Camellia japonica. On the other hand, the posterior of Aucuba japonica was less than zero within 95\% CI (Fig. 3A). The posterior mean of the random effect was -3.80 and the expected value of survival probability was $0.2 \%$. The posterior mean of Vaccinium bracteatum Thunb. was the second smallest and the value was -3.03 ; the expected survival probability was $0.4 \%$. Species without surviving individuals had nearly zero means and wider CIs, such as for Zanthoxylum ailanthoides. Random species effects on the survival coefficients of the gap predictor were rather small as absolute values and included zero in their $90 \%$ CI for all species (Fig. 3B).

Random species effects on intercepts of colonization from 1992 to 2014 were the largest in Quercus glauca, followed by Eurya japonica, Cleyera japonica, Symplocos prunifolia, Photinia glabra, and so on (Fig. 4A). The posterior mean of the random effect for Quercus glauca was 6.09 and the expected colonization probability without the gap effects was $90.7 \%$. In the same manner, the expected colonization probabilities for Cleyera japonica, Symplocos prunifolia, and Photinia glabra were 28.3\%, 26.7\%, and $14.1 \%$, respectively.

Random species effects on the colonization coefficient of the gap predictor were the largest for Callicarpa mollis Siebold et Zucc., followed by Zanthoxylum ailanthoides, Carpinus tschonoskii, Triadica sebifera, and so on. They were the smallest in Cleyera japonica. The posterior mean of the random effect for Callicarpa mollis was 2.32, so that the expected colonization probability for the species in the gap quadrats was estimated to be $25.9 \%(=1 /(1+\exp (3.81-1.51+1.07-2.32)))$, as the posterior mean of the random species effect on the colonization for the species was -1.07. Some species such as Quercus glauca had wider CI in their posteriors. This might be because there was little information for such species due to the small number of colonizers within the gaps (Fig. 4B).

Complete estimates of random effects are available in Table S3. 


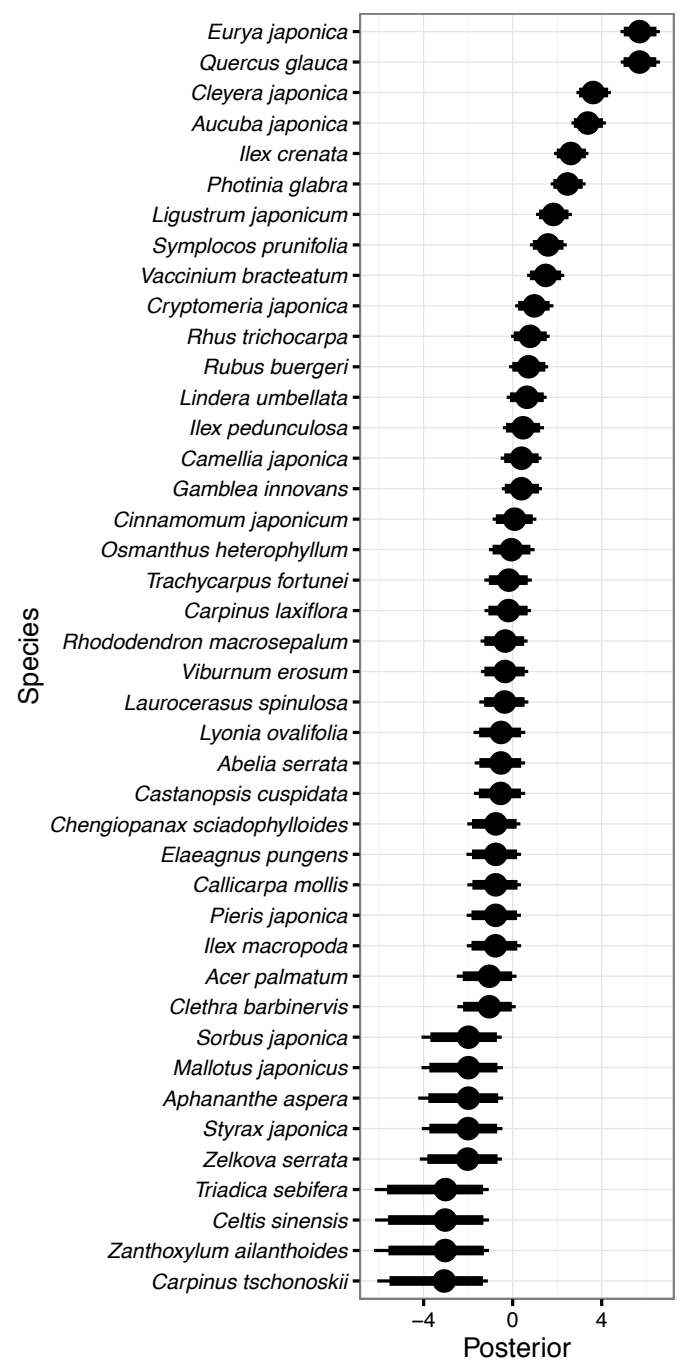

Figure 2. Random species effects on occurrence in $1992 \varepsilon_{0}$.

Thin lines denote $95 \%$ credible intervals (CI), thick lines denote $90 \%$ CI, and circles denote medians. Larger positive values in the posterior indicate that the species will be more likely to be present in 1992 than the overall mean, and negative values indicate that the species will be less likely. 

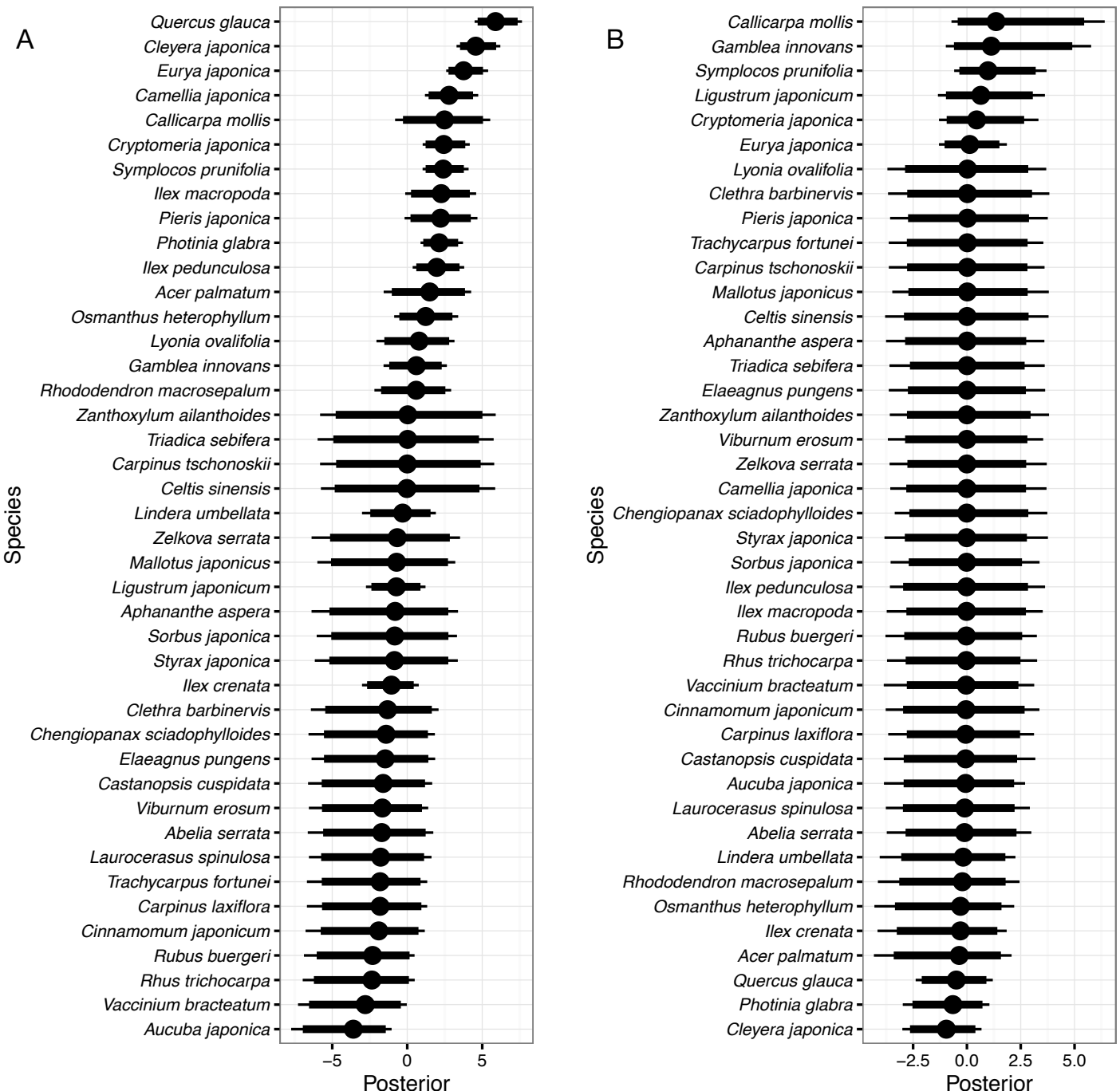

Figure 3. Random species effects on survival.

(A) $\varepsilon_{\mathrm{s}}$, on the intercept, and (B) $\varepsilon_{\mathrm{sg}}$, on the coefficient of the effect of gap. Thin lines denote $95 \%$ credible intervals (CI), thick lines denote $90 \%$ CI, and circles denote medians. Larger positive values in the posterior indicate that a species that had been present in a quadrat in 1992 will be more likely to be present in the same quadrat in 2014 than the overall mean, and negative values indicate that the species will be less likely. 

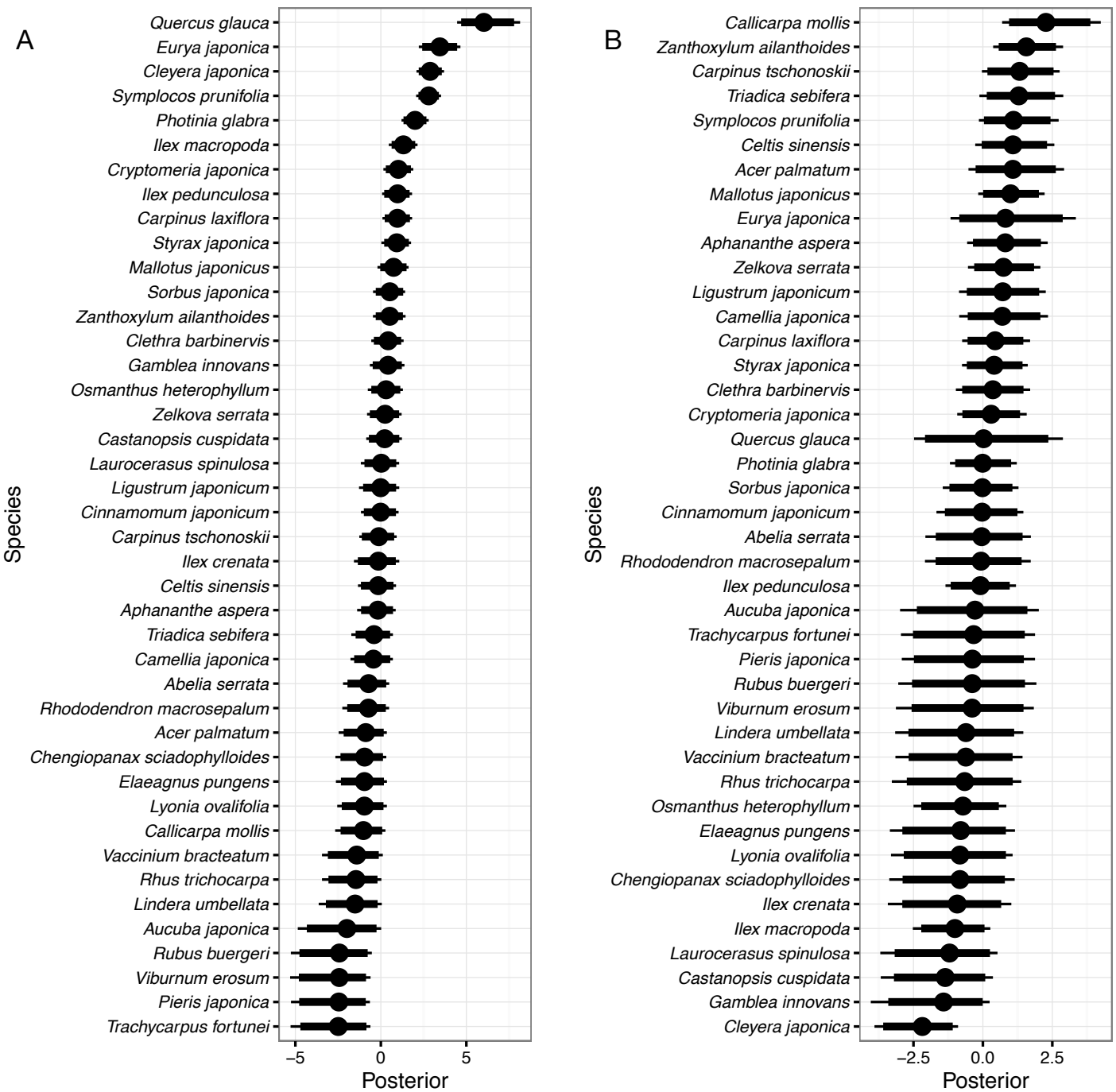

Figure 4. Random species effects on colonization. (A) $\varepsilon_{\mathrm{c}}$, for the intercept and (B) $\varepsilon_{\mathrm{cg}}$, for the coefficient of the gap effect. Thin lines denote $95 \%$ credible intervals (CI), thick lines denote $90 \%$ CI, and circles denote medians. Larger positive values in the posterior indicate that species that had been absent in a quadrat in 1992 will be more likely to be present in the same quadrat in 2014 than the overall mean, and negative values indicate that the species will be less likely. 


\section{DISCUSSION}

The mean probability of overall occurrence in 1992 for individual species was estimated to be only $3.7 \%$ for each quadrat. This reflects the fact that many species occurred only in a small fraction of the quadrats. The most frequent species in 1992 were all evergreen tree or shrub species such as Eurya japonica, Quercus glauca, Cleyera japonica, Aucuba japonica, Ilex crenata, and Photinia glabra; the expected occurrence probabilities of these species were all larger than $30 \%$. Species with large values of random species effects concerning occurrence corresponded to these species as a matter of course (Fig. 2). On the other hand, the least frequently occurring species were deciduous trees or shrubs such as Carpinus tschonoskii, Zanthoxylum ailanthoides, Celtis sinensis Pers., and Triadica sebifera; these species were not detected in the quadrats in 1992. The canopy of the forest was almost closed in 1992, so that shade-tolerant evergreen tree or shrub species dominated the understory layer and deciduous early-successional species infrequently occurred.

Overall survival and colonization probability by individual species were expected to be $6.9 \%$ and $2.2 \%$, respectively, on average. These may seem small, but some species have large random effect values allowing them to survive or colonize at high probabilities. The average colonization probability was estimated to increase in the gap quadrats. This was in accord with the preceding study showing that gap creation increased floor species richness even under deer pressure (Suzuki, 2013).

The species that had the highest survival probability in the non-gap quadrats was Quercus glauca (Fig. 3A); the mean probability of survival was expected to be $96.5 \%$. Quercus glauca produces many sprouts (Cai, 2000), and the sprouts may survive when the main stems die. This trait might contribute to the high survival probability. Cleyera japonica, Eurya japonica, and Camellia japonica followed Quercus glauca in their survival probabilities. These species, including Quercus glauca, were all evergreen broadleaved species that could survive under a closed canopy, as shown by their occurrence. In contrast, Aucuba japonica, a species of evergreen shrub, had the smallest survival probability at $0.2 \%$. This species was found in 107 of 200 quadrats in 1992, but never found in 2014. Aucuba japonica is known to be a preferred food for sika deer and is vulnerable to deer browsing (Hashimoto and Fujiki, 2014). The encroachment of deer likely explains its small survival probability. The posterior mean of the random effect was the second smallest in Vaccinium bracteatum. There is relatively little information on the palatability of Vaccinium bracteatum for sika deer, and some reports refer to it as a food plant, while others refer to it as unpalatable (Nakajima, 1929; Kabaya, 1988; Takatsuki, 1989; Hashimoto and Fujiki, 2014). The present results suggest that the species is vulnerable to deer impacts. The random species effects on the survival coefficients of the gap predictor were not so clear (Fig 3B. This may due both to the small sample size of the gap quadrats, and to the small number of light-demanding species occurring in 1992.

The colonization probability in the non-gap quadrat was highest in Quercus glauca, and evergreen shrub or sub-canopy trees followed (Fig. 4A). Among them, Quercus glauca had an especially high colonization probability; the expected value was $90.7 \%$. This might be because numerous seeds of this species are dispersed in the forest due to the abundance of mother trees (Itô, 2007; Itô, 2015), and it could persist at the 
seedling stage (Itô, 2009). On the other hand, the four species whose colonization probabilities were largest in the gaps are all shade-intolerant (Shimoda et al., 1994; Shibata and Nakashizuka, 1995). In addition to the four species, Symplocos prunifolia is also considered to be a shade-intolerant species though it is an evergreen (Fujii, 1994). However, Symplocos prunifolia and Triadica sebifera are unpalatable plants for sika deer (Shimoda et al., 1994; Hashimoto and Fujiki, 2014). Triadica sebifera is an alien species in Japan. The species is unpalatable for sika deer (Shimoda et al., 1994; Hashimoto and Fujiki, 2014), and as of 2002, it was increasing on Mt. Kasugayama (Maesako et al., 2007). Shimoda et al. (1994) studied the deer effects on pioneer species on Mt. Kasugayama, where deer population density was high; the authors found that pioneer species including Zanthoxylum ailanthoides and Callicarpa mollis emerged in gaps but rarely survived or matured due to deer foraging pressure.

In the study site, few large stems (height $\geq 50 \mathrm{~cm}$ ) of Zanthoxylum ailanthoides, Callicarpa mollis, and Carpinus tschonoskii were found, though a greater number of those of Quercus glauca, Cleyera japonica, and Eurya japonica were found in the quadrats that were not affected by the mass oak mortality (Itô, 2015). The latter species are evergreen trees or shrubs, and they had been dominant at least since 1992. In addition to these species, large plants of Symplocos prunifolia and Triadica sebifera were found in the gap quadrats created, expanded, or affected by the mass mortality (Itô, 2015), and the high colonization rate of these species in the gaps might contribute to their regeneration. Suzuki (2013) pointed out that succession after the abandonment of coppices in which there was gap creation under deer herbivory pressure would increase dominance by shade-tolerant and herbivory-tolerant species. In the present study, the two shade-intolerant and deer-unpalatable species frequently colonized into the gap quadrats and grew up. The difference may be due to the abundance of the two species or overall differences in species composition; for example, the shade-tolerant and herbivorytolerant species Maesa japonica (Thunb.) Moritzi et Zoll. present in the gap plots of (Suzuki, 2013) was not found in the present study site.

Horsley et al. (2003) conducted a field experiment in a hardwood forest in Pennsylvania, North America, and showed that fern abundance increased in thinned and clear-cut stands with an increase in deer density while the abundance of Rubus and tree seedlings decreased. Horsley et al. (2003) pointed out that the established ferns could interfere with the buildup of tree seedlings and the restoration of diversity. Obora et al. (2013) studied the effect of deer herbivory on forest regeneration after the mass mortality of oak trees and found that only some unpalatable fern species increased under deer herbivory, while many species including trees increased within exclosures. Obora et al. (2013), however, also mentioned that the tree species were suppressed by shrub and grass species even in the exclosures. This suggests the difficulty of forests regenerating from damage caused by the mass mortality of oak trees. A similar issue was also reported in (Itô et al., 2011), in a forest subjected to mass mortality and whose floor was dominated by dwarf bamboo. In the present study, such shrub or grass species were lacking, but a deer-unpalatable fern, Hypolepis punctata (Thunb.) Mett. ex Kuhn, partially colonized the gap quadrats (Itô, 2015). Such deer-unpalatable ferns and/or herbaceous species may suppress regeneration of tree species, and colonize gaps, resulting in dominance of the forest floor. 


\section{CONCLUSION}

Gaps that were created, expanded, or affected by the mass mortality of oak trees might increase colonization of pioneer species. Shade-intolerant species such as Callicarpa mollis, Zanthoxylum ailanthoides, Carpinus tschonoskii, Triadica sebifera, and Symplocos prunifolia were estimated to more frequently colonize the gaps. Among them, deer-unpalatable Symplocos prunifolia and Triadica sebifera may be more likely to survive or mature under foraging pressure of deer, while deer-palatable species such as Callicarpa mollis and Zanthoxylum ailanthoides may be unlikely to grow under such pressure. This may change the species composition in regenerating stands.

In the future, deer-unpalatable species such as Symplocos prunifolia and Triadica sebifera may dominate the understory within the gaps that are created, expanded, or affected by the mass mortality of oak trees rather than the current dominant species such as Eurya japonica and Quercus glauca, while these current dominant species may retain their dominance within unaffected areas owing to their abundance and shade-tolerance under the current magnitude of deer pressure.

\section{ACKNOWLEDGEMENTS}

I thank Dr. K. Hirayama (Kyôto Prefectural University) for cooperating with the fieldwork and the Kyôto-Ôsaka District Forest Office for supporting this work. I also thank Dr. H. Iijima (Yamanashi Forest Research Institute) for reading a previous version of the manuscript and for comments. Computational calculations were conducted on the high-performance cluster computing system of AFFIT, Ministry of Agriculture, Forestry and Fisheries, Japan.

\section{REFERENCES}

Brooks, S. P. and Gelman, A. (1998). General methods for monitoring convergence of iterative simulations. Journal of Computational and Graphical Statistics, 7:434-455.

Cai, F. (2000). A study on the structure and dynamics of Cyclobalanopsis glauca population at hills around West Lake in Hangzhou. Scientia Silvae Sinicae, 36:67-72. (in Chinese with English summary).

Chen, G., Kéry, M., Plattner, M., Ma, K., and Gardner, B. (2013). Imperfect detection is the rule rather than the exception in plant distribution studies. Journal of Ecology, 101:183-191.

Chen, G., Kéry, M., Zhang, J., and Ma, K. (2009). Factors affecting detection probability in plant distribution studies. Journal of Ecology, 97:1383-1389.

Côté, S. D., Rooney, T. P., Tremblay, J.-P., Dussault, C., and Waller, D. M. (2004). Ecological impacts of deer overabundance. Annual Review of Ecology and Systematics, 35:113-147.

Dorazio, R. M., Royle, J. A., Söderström, B., and Glimskär, A. (2006). Estimating species richness and accumulation by modeling species occurrence and detectability. Ecology, 87:842-854.

Fujii, T. (1994). Stand development process and flowering patterns of a Symplocos prunifolia population. Humans and Nature, 3:79-83. (in Japanese with English summary). 
Gelman, A., Carlin, J. B., Stern, H. S., Dunson, D. B., Vehtari, A., and Rubin, D. B. (2013). Bayesian data analysis. CRC Press, Boca Raton, 3rd edition.

Gelman, A. and Rubin, D. B. (1992). Inference from iterative simulation using multiple sequences. Statistical Science, 7:457-472.

Hashimoto, Y. and Fujiki, D. (2014). List of food plants and unpalatable plants of sika deer (Cervus nippon) in Japan. Humans and Nature, 25:133-160. (in Japanese).

Horsley, S. B., Stout, S. L., and DeCalesta, D. S. (2003). White-tailed deer impact on the vegetation dynamics of a northern hardwood forest. Ecological Applications, 13:98-118.

Ida, H. and Takahashi, S. (2010). Mass mortality of oak trees had already occurred at the Edo period. Journal of Japanese Forest Society, 92:115-119. (in Japanese with English summary).

Iijima, H. and Nagaike, T. (2015). Appropriate vegetation indices for measuring the impacts of deer on forest ecosystems. Ecological Indicators, 48:457-463.

Itô, H. (2007). Twelve-years change of a broad-leaved secondary forest in Ginkakuji-san National Forest. Bulletin of FFPRI, 6:93-100. (in Japanese with English summary). Itô, H. (2009). A comparison of seedling emergence and survival between Quercus glauca and Symplocos prunifolia. Journal of Forest Research, 14:245-250.

Itô, H. (2015). Effects of sika deer (Cervus nippon) on the dynamics of a broadleaved secondary forest after mass mortality of oak trees. Journal of Japanese Forest Society, 97:304-308. (in Japanese with English summary).

Itô, H., Igarashi, T., and Kinuura, H. (2009). Changes in stand structure after the mass mortality of oak trees in Keihoku area, Kyoto City, Japan. Journal of Japanese Forestry Society, 91:15-20. (in Japanese with English summary).

Itô, H., Kinuura, H., and Oku, H. (2011). Stand structure of a broadleaved forest with Sasa-type floor after mass mortality by oak wilt disease. Journal of Japanese Forestry Society, 93:84-87. (in Japanese with English summary).

Kabaya, H. (1988). Changes of undergrowth of a broadleaved evergreen forest in relation to grazing effects by sika deer. Bulletin of the Tokyo University Forests, 78:67-82. (in Japanese with English summary).

Kéry, M. (2004). Extinction rate estimates for plant populations in revisitation studies: importance of detectability. Conservation Biology, 18:570-574.

Kéry, M. and Schaub, M. (2012). Bayesian population analysis using WinBUGS: a hierarchical perspective. Academic Press, Waltham.

Kinuura, H. and Kobayashi, M. (2006). Death of Quercus crispula by inoculation with adult Platypus quercivorus (Coleoptera: Platypodidae). Applied Entomology and Zoology, 41:123-128.

Kobayashi, M. and Ueda, A. (2005). Wilt disease of Fagaceae trees caused by Platypus quercivorus (murayama) (Coleoptera: Platypodidae) and the associated fungus: aim is to clarify the damage factor. Journal of Japanese Forest Society, 87:435-450. (in Japanese with English summary).

Kubono, T. and Ito, S.-i. (2002). Raffaelea quercivora sp. nov. associated with mass mortality of Japanese oak, and the ambrosia beetle (Platypus quercivorus). Mycoscience, 43:255-260.

Kuroda, K., Osumi, K., and Oku, H. (2012). Reestablishing the health of secondary forests "Satoyama" endangered by Japanese oak wilt: A preliminary report. Journal 
of Agricultural Extension and Rural Development, 4:192-198.

Lunn, D., Spiegelhalter, D., Thomas, A., and Best, N. (2009). The bugs project: Evolution, critique, and future directions. Statistics in Medicine, 28:3049-3067.

Maesako, Y., Nanami, S., and Kanzaki, M. (2007). Spatial distribution of two invasive alien species, Podocarpus nagi and Sapium sebiferum, spreading in a warm-temperate evergreen forest of the Kasugayama Forest Reserve, Japan. Vegetation Science, 24:103-112.

Müllerová, J., Hédl, R., and Szabó, P. (2015). Coppice abandonment and its implications for species diversity in forest vegetation. Forest Ecology and Management, 343:88100.

Murata, M., Matsuda, Y., Yamada, T., and Ito, S. (2009). Differential spread of discoloured and non-conductive sapwood among four Fagaceae species inoculated with Raffaelea quercivora. Forest Pathology, 39:192-199.

Murata, M., Yamada, T., and Ito, S.-i. (2005). Changes in water status in seedlings of six species in the Fagaceae after inoculation with Raffaelea quercivora Kubono et Shin-Ito. Journal of Forest Research, 10:251-255.

Naka, K. (1982). Community dynamics of evergreen broadleaf forests in southwestern Japan. I. Wind damaged trees and canopy gaps in an evergreen oak forest. Botanical Magazine Tokyo, 95:385-399.

Nakajima, H. and Ishida, M. (2014). Decline of Quercus crispula in abandoned coppice forests caused by secondary succession and Japanese oak wilt disease: Stand dynamics over twenty years. Forest Ecology and Management, 334:18-27.

Nakajima, M. (1929). The feeding experiments of Japanese deer in the university forest in Chiba prefecture. Bulletin of the Tokyo University Forests, 8:95-114. (in Japanese). Obora, T., Watanabe, H., and Yokoi, S. (2013). The effect of Sika deer browsing damage on regeneration in mass mortality area of Japanese oak trees. Journal of Japanese Society of Revegetation Technology, 39:260-263. (In Japanese).

Rackham, O. (2008). Ancient woodlands: Modern threats. New Phytologist, 180:571586.

Rooney, T. P. (2001). Deer impacts on forest ecosystems: a North American perspective. Forestry, 74:202-208.

Saito, S. and Shibata, M. (2012). The forest structure and tree death rate of forest stands damaged by Japanese oak wilt in Yamagata prefecture. Journal of Japanese Forest Society, 94:223-228. (in Japanese with English summary).

Shibata, M. and Nakashizuka, T. (1995). Seed and seedling demography of four cooccurring Carpinus species in a temperate deciduous forest. Ecology, 76:1099-1108.

Shimoda, K., Kimura, K., Kanzaki, M., and Yoda, K. (1994). The regeneration of pioneer tree species under browsing pressure of Sika deer in an evergreen oak forest. Ecological Research, 9:85-92.

Suzuki, M. (2013). Succession of abandoned coppice woodlands weakens tolerance of ground-layer vegetation to ungulate herbivory: A test involving a field experiment. Forest Ecology and Management, 289:318-324.

Svátek, M. and Matula, R. (2015). Fine-scale spatial patterns in oak sprouting and mortality in a newly restored coppice. Forest Ecology and Management, 348:117-123.

Takatsuki, S. (1989). Effects of deer on plants and plant communities. Japanese Journal of Ecology, 39:67-80. (in Japanese with English summary). 
508 Takatsuki, S. (2009). Effects of sika deer on vegetation in Japan: A review. Biological Conservation, 142:1922-1929. 